\title{
Discontinuity in Equilibrium Wave-Current Ripple Size and Shape Caused by a Winnowing Threshold in Cohesive Sand-Clay Beds
}

\author{
X. Wu ${ }^{1}$, R. Fernández ${ }^{1}$, J. H. Baas ${ }^{2}$, J. Malarkey ${ }^{1,2}$, and D. R. Parsons ${ }^{1}$ \\ ${ }^{1}$ Energy and Environment Institute, University of Hull, Hull, HU6 7RX, England, U.K. \\ ${ }^{2}$ School of Ocean Sciences, Bangor University, Menai Bridge, LL59 5AB, Wales, U.K. \\ Corresponding author: Xuxu Wu (x.wu@hull.ac.uk) \\ Email addresses: \\ Twitter: \\ X.Wu@hull.ac.uk \\ R.Fernandez@hull.ac.uk \\ @ stickyripple \\ J.Baas@bangor.ac.uk \\ J.Malarkey@bangor.ac.uk \\ @icemeanders \\ D.Parsons@hull.ac.uk \\ @ making_ripples \\ NA \\ @bedform
}

This is a non-peer reviewed preprint submitted to EarthArXiv. The manuscript has been submitted to the Journal of Geophysical Research: Earth Surface and is currently under consideration. Feel free to contact any of the authors with queries or to offer constructive feedback. 


\section{Discontinuity in Equilibrium Wave-Current Ripple Size and Shape Caused by a Winnowing Threshold in Cohesive Sand-Clay Beds}

\section{Wu ${ }^{1}$, R. Fernández ${ }^{1}$, J. H. Baas ${ }^{2}$, J. Malarkey ${ }^{1,2}$, and D. R. Parsons ${ }^{1}$}

${ }^{1}$ Energy and Environment Institute, University of Hull, Hull, HU6 7RX, England, U.K.

${ }^{2}$ School of Ocean Sciences, Bangor University, Menai Bridge, LL59 5AB, Wales, U.K.

Corresponding author: Xuxu Wu (x.wu@hull.ac.uk)

\section{Key Points:}

- Ripple growth-rates decrease with increasing initial bed clay content in sand-clay substrates under combined, wave-current, flows.

- Large ripples, comparable to clean-sand ones, can form below a clay content threshold, due to efficient winnowing of bed-clay.

- Small, flat ripples prevail when the clay content is above the threshold and strong bed cohesion prevents ripple growth. 


\section{Abstract}

Sediments composed of mixed cohesive clay and non-cohesive sand are widespread in a range of aquatic environments. The dynamics of ripples in mixed sand-clay substrates have been studied under pure current and pure wave conditions. However, the effect of cohesive clay on ripple development under combined currents and waves has not been examined, even though combined flows are common in estuaries, particularly during storms. Based on a series of flume experiments, we identified robust inverse relationships between initial bed clay content, $C_{0}$, and wave-current ripple growth-rates. The experimental results also revealed two distinct types of equilibrium ripples on mixed sand-clay beds: (a) large asymmetrical ripples with geometries comparable to clean-sand counterparts for $C_{0} \leq 10.6 \%$; and (b) small, flat ripples for $C_{0}>11 \%$. The increase in bed cohesion contributed to this discontinuity, expressed most clearly in a sharp reduction in equilibrium ripple height, and thus a significant reduction in bed roughness, which implies that the performance of existing ripple predictors can be improved by the incorporation of this physical cohesive effect. For $C_{0} \leq 10.6 \%$, strong clay winnowing efficiency under combined flows resulted in the formation of equilibrium clean-sand ripples and clay loss at depths far below the ripple base. In natural environments, this 'deep cleaning' of bed clay may cause a concurrent sudden release of a large amount of pollutants during storms, leading to a sudden reduction in post-storm resistance to erosion of mixed sand-clay substrates and reduced water quality.

\section{Plain Language Summary}

Sticky-mud and sand are commonly found on estuary beds. Particularly during storms, the combined effect of waves and currents can erode the bed, creating small undulating shapes called ripples. For sand-only beds, the size of the ripples depends on the strength of the waves and currents that create them, and the size of the sand grains (fine sand is easier to erode than coarse sand). However, when sticky-mud is present, the growth of the ripples slows down. This study has 
identified that when waves and currents act at the same time: (1) Estuary beds with mixtures of sticky-mud and sand can form ripples with similar shape and size as clean-sand counterparts if the initial sticky-mud content is less than approximately $11 \%$; (2) Estuary beds with an initial stickymud content higher than approximately $11 \%$ cannot be eroded and form very small ripples that are prevented from growing further due to the strength of the sticky-mud. The $11 \%$ threshold identified in this study is specific to the waves and currents tested, but the findings are generalizable and more research is required to identify the threshold under different wave-current combinations to better predict flow behaviours in muddy estuaries throughout the world.

\section{Introduction}

Ripples are primary sedimentary structures that are ubiquitous on the bed of estuaries and coastal seas. These bedforms often preserve information of the flow parameters by which they were formed (e.g., Southard, 1991, Soulsby and Clarke, 2005). Ripple-related bed roughness in turn modifies near-bed hydrodynamics and turbulence, ultimately affecting sediment fluxes, a process which is essential for the modelling of sediment transport (e.g., Soulsby, 1997, Van Rijn, 2007). Many estuarine and coastal environments face extreme weather events, which are predicted to increase in frequency with rising sea levels (e.g., Woodruff et al., 2013). Storm-induced waves combined with currents cause particularly dynamic ripple behaviour, and thus high and rapidly changing sediment transport rates (e.g., Li and Amos, 1999, Wengrove et al., 2018). The understanding of how hydrodynamics control ripple dimensions is therefore essential for ensuring the improved performance of coastal morphodynamic models through well-parameterised bed roughness. This is also beneficial for the improvement of estuarine and coastal management and the broader understanding the impact of climate change and sea level rise on coastal systems. Furthermore, using inverse relationships to predict hydrodynamic variables from ripples preserved 
in sedimentary rocks is essential for the accurate reconstruction of paleoenvironments (e.g., Rubin and Carter, 2005, Myrow et al., 2018). Finally, in view of the nutrient cycle of the coastal ecosystem, ripples have a significant effect on the exchange of dissolved substances between the water column and the seabed, providing organic matter to benthic communities and returning the decompositional products as nitrogen resources for phytoplankton (e.g., Nedwell et al., 1993, Snelgrove and Butman, 1995, Huettel et al., 1996).

Flume studies have provided high-quality process information concerning ripple dynamics on beds composed of well-sorted clean sand under steady currents (e.g., Baas, 1994, Baas, 1999), waves (e.g., Pedocchi and García, 2009, O'Hara Murray et al., 2011), and combined wave and current flows (e.g., Dumas et al., 2005, Perillo et al., 2014b). Empirical formulae developed for the prediction of ripple size have been derived from clean sand ripples in laboratories and at field sites (e.g., Khelifa and Ouellet, 2000, Nelson et al., 2013, Lapotre et al., 2017). However, these ripple size predictors are of limited use for the majority of estuarine and coastal environments, where sediment almost universally consists of mixture of cohesive clay and non-cohesive sand (Healy et al., 2002). Recently, researchers have therefore focused on ripple dynamics within substrates composed of mixtures of sand and clay. For steady currents with a depth-averaged velocity of $0.36 \mathrm{~m} / \mathrm{s}$, Baas et al. (2013) found that equilibrium ripple height decreased with increasing initial clay content. Wu et al. (2018) highlighted that a small increase in clay content, from $4.2 \%$ to $7.4 \%$, exponentially increased the time needed for ripples to reach equilibrium under waves with a maximum free stream velocity of $\sim 0.35 \mathrm{~m} / \mathrm{s}$. However, the equilibrium dimensions of these wave ripples were independent of the initial clay content in the bed, up to around $8 \%$. Additionally, clay winnowing, a hydrodynamic sorting process which suspends the finer clay but leaves the coarser sand in the bed (e.g., Cizeau et al., 1999), played a significant role in the transformation of ripples 
in mixed sand-clay to an increasingly sandy composition in the experiments of Baas et al. (2013) and $\mathrm{Wu}$ et al. (2018). Importantly, Baas et al. (2019) has recently highlighted the role of bed cohesion in decreasing current ripple dimensions in the Dee Estuary, U.K., demonstrating that previous laboratory findings are applicable in natural environments. There has, however, been very little research on the dynamics of ripples in mixed sand-clay beds under combined wave-current flows, which are crucial to the sediment dynamics in the majority of estuaries and coastal seas. This paper therefore extends the experimental work of Baas et al. (2013) and Wu et al. (2018) by providing the first results of the influence of cohesive clay on ripple dynamics by means of flume experiments under combined flows. The three specific objectives were: (1) to quantify ripple development rates for different initial bed clay fractions; (2) to determine the relationship between the equilibrium ripple dimensions and initial bed clay content; and (3) to relate the ripple development to the changing bed composition, based on quantifying clay winnowing from the bed into the water column.

\section{Materials and Methods}

\subsection{Experimental Setup}

A series of large flume experiments were conducted in the Total Environment Simulator at the University of Hull. Three channels of equal size $(11 \mathrm{~m}$ in length and $1.4 \mathrm{~m}$ in width, with brick walls $0.2 \mathrm{~m}$ in height) were constructed in a recirculating tank, with a gravel section of one metre in length at the upstream end to allow for boundary layer development and an artificial beach made of polyethylene foam at the downstream end to damp out wave reflections (Figure 1a). A crosstank mobile gantry centred $3.5 \mathrm{~m}$ downstream of the inlet and capable of traversing $2 \mathrm{~m}$ downstream held most measurement sensors. A flat sediment bed, $0.1 \mathrm{~m}$ thick, was present in each channel at the start of the experiments. Fresh water was used in all experiments, and the water 
107 depth, $h$, was set to $0.4 \mathrm{~m}$ in the test section. Control Run 1 used three beds of well-sorted sand with a median diameter, $D_{50}$, of $450 \mu \mathrm{m}$. Runs 2 and 3, which considered the effect of physical cohesion, used a homogenous mix of kaolinite clay with $D_{50}=8.9 \mu \mathrm{m}$ and the same sand. Six beds were prepared with initial clay content varying from $5.7 \%$ to $12.3 \%$ by dry weight (Table 1 ).

Table 1. Experimental parameters

\begin{tabular}{|c|c|c|c|c|c|c|c|}
\hline Run & $\begin{array}{c}\text { Duration } \\
(\min )\end{array}$ & Channel $^{*}$ & $\begin{array}{c}C_{0} \\
(\%)\end{array}$ & $\begin{array}{c}U_{o} \\
(\mathrm{~m} / \mathrm{s})\end{array}$ & $\begin{array}{c}U_{c} \\
(\mathrm{~m} / \mathrm{s})\end{array}$ & $\begin{array}{c}U_{\max } \\
(\mathrm{m} / \mathrm{s})\end{array}$ & $\begin{array}{c}U_{\min } \\
(\mathrm{m} / \mathrm{s})\end{array}$ \\
\hline 1 & 1970 & 2 & 0 & 0.32 & 0.16 & 0.45 & -0.01 \\
\hline 2 & 2000 & 2 & 10.6 & 0.31 & 0.15 & 0.44 & -0.01 \\
\cline { 3 - 8 } & & 3 & 12.3 & 0.33 & 0.20 & 0.51 & -0.01 \\
\hline \multirow{2}{*}{3} & \multirow{2}{*}{1250} & 1 & 5.7 & 0.32 & 0.19 & 0.4 & -0.08 \\
\cline { 3 - 8 } & & 2 & 8.5 & 0.31 & 0.16 & 0.45 & -0.01 \\
\cline { 3 - 8 } & & 3 & 11.6 & 0.33 & 0.19 & 0.50 & -0.01 \\
\hline
\end{tabular}

112

113

114

115

116

117

* Data for channel 1 of Run 2 is excluded because clay and sand were not mixed homogeneously.

Each run was carried out using combined flows. Flow velocities in each channel were measured by a $25 \mathrm{~Hz}$ Vectrino profiler fixed on the gantry beam $4.5 \mathrm{~m}$ away from the flume inlet and at 0.12 metres above the initial flat bed (Figure 1a). The monochromatic wave height, $H$, and wave period, $T$ were c. $0.17 \mathrm{~m}$ and $2 \mathrm{~s}$, respectively, measured by eight $50 \mathrm{~Hz}$ acoustic water level sensors 0.7 $\mathrm{m}$ above the still water surface in the tank (Figure $1 \mathrm{~b}$ ). The wave velocity amplitude at the edge of the boundary layer, $U_{o}$, was c. $0.32 \mathrm{~m} / \mathrm{s}$, and the depth-averaged current velocity, $U_{c}$, was c. 0.16 $\mathrm{m} / \mathrm{s}$. Although there was a small variation in velocities across the flume tank, this did not significantly influence ripple evolution (Table 1). The waves in the experiments were skewed shallow-water waves with sharp crests and long troughs, generating a maximum combined flow velocity, $U_{\max }$, of c. $0.45 \mathrm{~m} / \mathrm{s}$ and a minimum combined flow velocity, $U_{\min }$, of c. $-0.01 \mathrm{~m} / \mathrm{s}$ at a height above the bed of $0.05 \mathrm{~m}$, when combined with the current (Table 1). Near the bed, the 
strongly non-linear option proposed by Malarkey and Davies (2012) for calculating the mean bed shear stress, $\tau_{\mathrm{m}}$, and maximum bed shear stress, $\tau_{\max }$, gives $\tau_{\mathrm{m}}=0.14 \mathrm{~Pa}$ and $\tau_{\max }=1.41 \mathrm{~Pa}$. These values are associated with a skin friction roughness of $2.5 D_{50}\left(z_{0}=2.5 D_{50} / 30\right.$, where $z_{0}$ is the theoretical height of zero velocity) in wave-current flow and are calculated with $h, U_{o}, T$ and $U_{c}$. The minimum bed shear stress, $\tau_{\min }=\tau_{\mathrm{m}}-\tau_{\max }$, was $-1.27 \mathrm{~Pa}$, indicating that bed shear stress was far more symmetric in the two wave half cycles than velocity higher up in the flow.

a. ${ }^{\uparrow}$

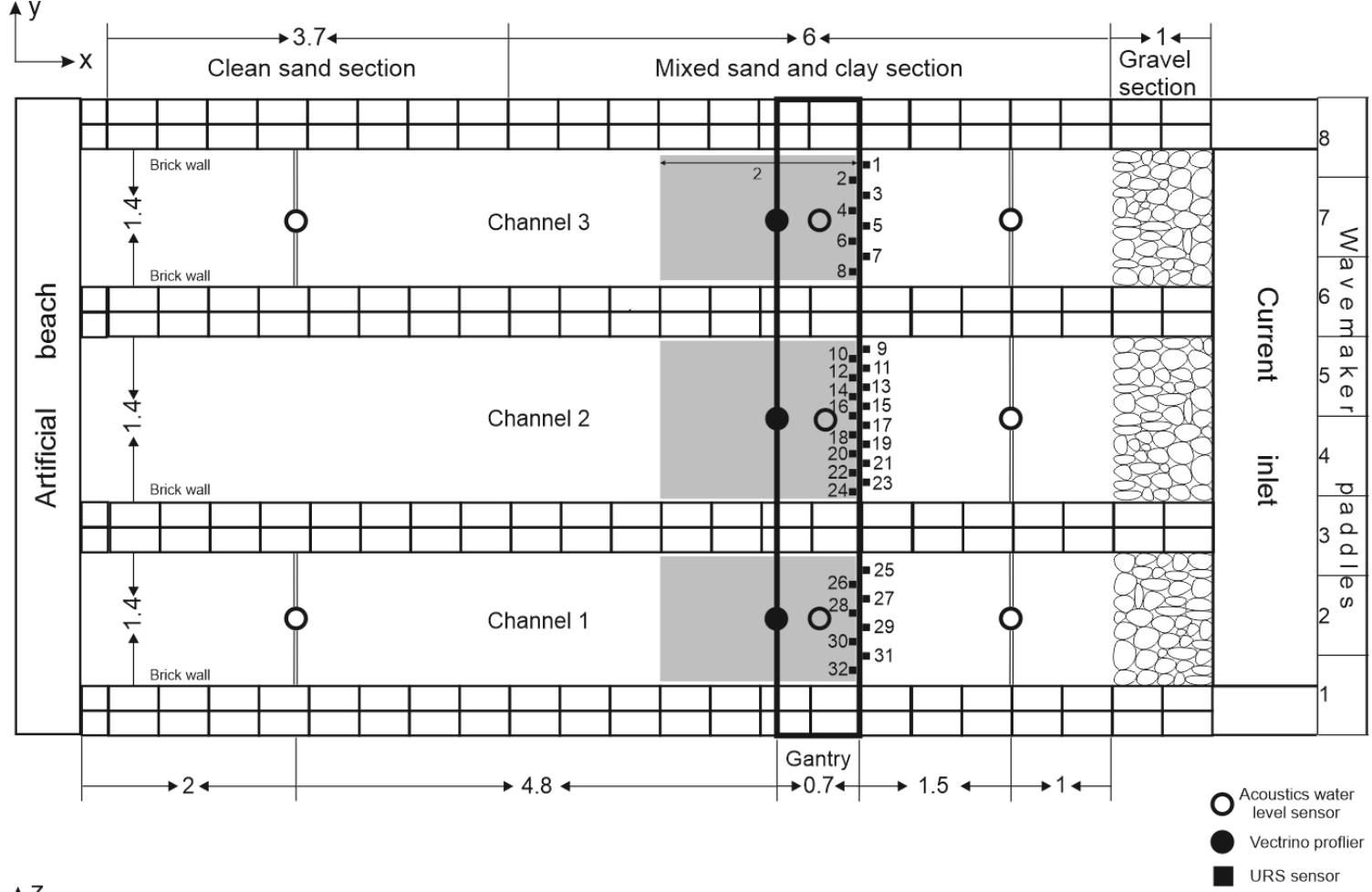

b. $\wedge$ Z

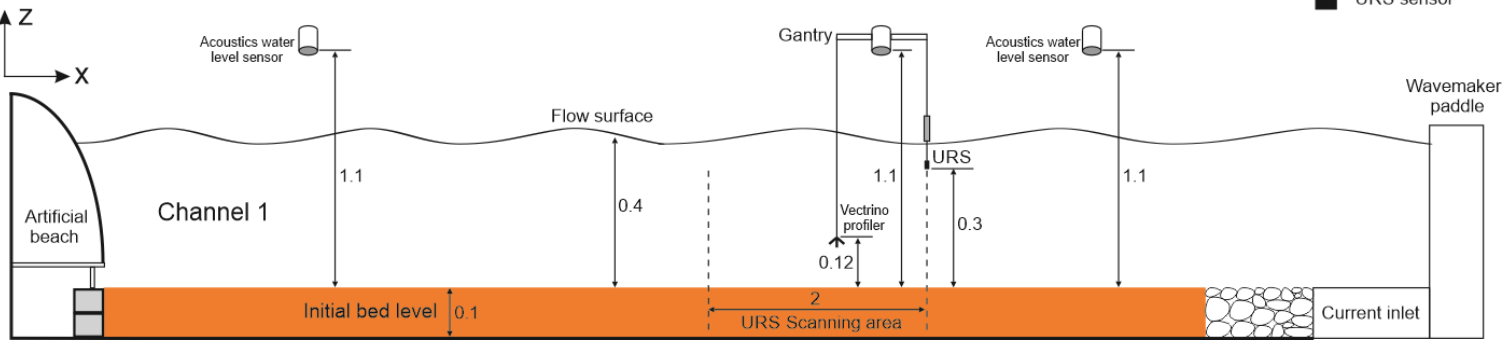

Figure 1. (a) Plan view and (b) Side view of the experimental set-up. The grey area is 


\subsection{Procedure}

The clay was homogeneously mixed into the sand using a handheld plasterer's mixer inside each channel flattened using a wooden leveller, and scanned using a terrestrial 3D laser scanner (FARO Focus3D X330). At the start of each experiment, syringe-type sediment cores with a diameter of $20 \mathrm{~mm}$ and a maximum length of $90 \mathrm{~mm}$ were collected from six locations at one-metre intervals along the centre lines of the mixed sand-clay sections. A homogenous sand-clay mix was present in all channels (Figure 5a, g, n), except for one substrate in Run 2, Channel 1, which was therefore excluded from the results presented below.

Bedform evolution was recorded in three dimensions using a Seatek $2 \mathrm{MHz}$ Ultrasonic Ranging System (URS) mounted on the gantry $4 \mathrm{~m}$ downstream of the flume inlet and $0.3 \mathrm{~m}$ above the bed. The URS contained 32 probes spatially distributed across the three channels (16 across Channel 2 and 8 across Channels 1 and 3). The array scanned at a fixed location during the flow and every time the flow was stopped, over an area two metres in length via an auto-traverse system that had a speed of $1 \mathrm{~mm} / \mathrm{s}$ (Figure 1).

Bed scanning was conducted at pre-set time intervals, gradually increasing from a 5 min interval in the initial phases of the runs, up to $180 \mathrm{~min}$ in the later phases of the experiments. Sediment syringe cores from the mixed clay and sand sections were also collected during the experiments whilst waves and currents were stopped. In Run 2, sediment cores were collected at two locations within the 2-metre scan swathe: near the start and near the end. One more collection location from the middle of the swathe was added in Run 3 because ripples with lower clay content were expected to develop faster and an additional sampling point could be beneficial to quantify winnowing. At each collection location, one core was taken from the initial flat bed and as soon as ripples were identified with the URS, a core was collected from the crest and a consecutive trough. After each experiment, the water was drained slowly from the tank and the rippled bed was scanned with the 
$1613 \mathrm{D}$ laser scanner, and sediment cores from neighbouring ripple crests and troughs were also 162 collected. Additional, sediment cores were collected from the ripples in the downstream clean sand

163 section in order to quantify the amount of clay that had re-entered the sandy substrate from being

164 in suspension. All sediment cores were stored in a cold store at a temperature of $4^{\circ} \mathrm{C}$ prior to grain

165 size analysis using a Malvern Mastersizer 2000. The sediment cores from the initial flat bed and 166 from the ripple troughs were sliced into $10 \mathrm{~mm}$ intervals for the grain size analysis; the cores

167 obtained from the ripple crests were sliced in $5 \mathrm{~mm}$ intervals to provide higher resolution of the 168 clay content within the ripples.

169 2.3. Postprocessing of Data

170 Ripple wavelengths, $\lambda$, and heights, $\eta$, were determined from the bed elevation profiles (BEP),

171 recorded by each URS sensor. The removal of spikes from the raw BEPs was based on $d z>d z_{m}$,

172 where $d z$ is the vertical distance between consecutive data points in the BEP and $d z_{m}$ is the average

173 vertical distance in the BEP (Van der Mark et al., 2008). Each BEP was then smoothed using a

174 three-point moving average, followed by applying MATLAB ${ }^{\circledR}$ 'peaks and troughs' tool to identify

175 the locations of ripple crests and troughs. The end-of-experiment cross-sectional shape of the

176 ripples was characterized by calculating the ripple steepness (RS) and ripple symmetry index

177 (RSI):

$$
R S=\frac{\eta}{\lambda}
$$

178

$$
R S I=\frac{\lambda_{s}}{\lambda_{l}}
$$


180 where $\lambda_{s}$ and $\lambda_{l}$ are the length of the stoss side and lee side, respectively. RSI values between 1 and

$181 \quad 1.3$ denote symmetrical ripples and RSI values higher than 1.5 represent increasingly asymmetrical

182 ripples. Ripples are quasi-asymmetrical for $1.3<\mathrm{RSI}<1.5$ (Perillo et al., 2014a).

183 Furthermore, the mean values of $\lambda_{t}$ and $\eta_{t}$ at a bed scanning time $t$ were calculated from all ripples

184 in the BEPs in each channel, in order to construct development curves of ripple wavelength and

185 height. Equilibrium ripple wavelength, $\lambda_{e}$, and height, $\eta_{e}$, and the time required to reach equilibrium

186 wavelength, $T_{\lambda}$, and height, $T_{\eta}$, were calculated using best-fit equations proposed by Baas et al.

187 (2013), which include a delay time for the first appearance of ripples on the flat bed, $t_{i}$ :

$$
\frac{\lambda_{t}-\lambda_{i}}{\lambda_{e}-\lambda_{i}}=1-0.1^{\frac{t-t_{i}}{T_{\lambda}-t_{i}}}
$$

188

$$
\frac{\eta_{t}}{\eta_{e}}=1-0.1^{\frac{t-t_{i}}{T_{\eta}-t_{i}}}
$$

190 where $\lambda_{e}, \eta_{e}, T_{\lambda}, T_{\eta}, \lambda_{\mathrm{i}}$, and $t_{i}$ are fitting coefficients, and $\lambda_{\mathrm{i}}$ is the initial wavelength of the first

191 ripples that appeared on the flat bed in each run. In this study, the equilibrium time was defined as

192 the time taken for the ripple wavelength or height to reach $90 \%$ of its equilibrium value (cf., Baas

193 et al., 2013). The coefficient $t_{i}$ was zero in the control run with clean sand (Table 2). All the fitting

194 coefficients for the combined flow ripples are listed in Table 2 and discussed in section 3. Finally,

195 characteristic ripple height growth rate, $r_{\eta}$, and wavelength growth rate, $r_{\lambda}$, over the experiment

196 were estimated as follows:

$$
r_{\eta}=\frac{\eta_{e}}{T_{\eta}}
$$




$$
r_{\lambda}=\frac{\left(\lambda_{e}-\lambda_{i}\right)}{T_{\lambda}}
$$

\section{3. Results}

\section{3.1. Ripple Development}

201 During the control run $\left(C_{0}=0 \%\right)$, small ripples appeared on the flat bed immediately after the 202 hydrodynamic forcing was applied, as evidenced by a five-min period of rapid growth, during 203 which the mean ripple wavelength and height reached $88.1 \mathrm{~mm}$ and $7.2 \mathrm{~mm}$, respectively. 204 Thereafter, the ripple growth rate progressively declined until the ripples stabilised (Figure 2a, b).

205 The development of these ripples exhibited a general trend similar to that reported in the combined 206 flows experiments of Perillo et al. (2014). Equations 3 and 4 revealed that the ripples took $170 \mathrm{~min}$ 207 and $90 \mathrm{~min}$ to reach an equilibrium wavelength and height of $123.6 \mathrm{~mm}$ and $14.6 \mathrm{~mm}$, respectively 208 (Table 2). These fully developed ripples were two-dimensional in planform geometry, 209 characterised by straight, continuous ripple crestlines (Figure 3a). The majority of the ripples were 210 symmetrical or quasi-asymmetrical, with a mean ripple symmetry index of 1.4 and a mean 211 steepness of 0.12 (Table 2), indicating that they were similar to wave-generated vortex ripples. 
Table 2. Ripple parameters

\begin{tabular}{|c|c|c|c|c|c|c|c|c|c|c|c|c|c|c|c|c|c|c|c|}
\hline Run & Channel & $\begin{array}{c}C_{0} \\
(\%)\end{array}$ & $\begin{array}{c}\eta_{e} \\
(\mathrm{~mm})\end{array}$ & $\begin{array}{c}\eta_{e} \\
\mathrm{SD} \\
(\mathrm{mm})\end{array}$ & $\begin{array}{c}\eta_{\text {end }} \\
(\mathrm{mm})\end{array}$ & $\begin{array}{c}T_{\eta} \\
(\mathrm{min})\end{array}$ & $r^{2}$ & $\begin{array}{c}\lambda_{e} \\
(\mathrm{~mm})\end{array}$ & $\begin{array}{c}\lambda_{e} \\
\mathrm{SD} \\
(\mathrm{mm})\end{array}$ & $\begin{array}{c}\lambda_{i} \\
(\mathrm{~mm})\end{array}$ & $\begin{array}{c}\lambda_{i} \\
\mathrm{SD} \\
(\mathrm{mm})\end{array}$ & $\begin{array}{c}\lambda_{\text {end }} \\
(\mathrm{mm})\end{array}$ & $\begin{array}{c}T_{\lambda} \\
(\min )\end{array}$ & $r^{2}$ & $\begin{array}{c}t_{i} \\
(\mathrm{~min})\end{array}$ & RSI & $\begin{array}{l}\text { RSI } \\
\text { SD }\end{array}$ & $\mathrm{RS}$ & $\begin{array}{l}\mathrm{RS} \\
\mathrm{SD}\end{array}$ \\
\hline 1 & 2 & 0 & 14.43 & 1.82 & 14.61 & 90 & 0.78 & 123.6 & 4.9 & 80.7 & 10.8 & 124.6 & 170 & 0.94 & - & 1.4 & 0.3 & 0.12 & 0.02 \\
\hline & 2 & 10.6 & 14.18 & 1.16 & 15.90 & 834 & 0.95 & 110.8 & 4.0 & 73.3 & 11.4 & 111.4 & 455 & 0.85 & 60 & 1.3 & 0.3 & 0.14 & 0.03 \\
\hline 2 & 3 & 12.3 & 3.50 & 0.31 & 4.25 & 211 & 0.79 & 98.0 & 1.7 & 71.7 & 6.3 & 98.7 & 722 & 0.93 & 120 & 1.5 & 0.5 & 0.04 & 0.02 \\
\hline \multirow{3}{*}{3} & 1 & 5.7 & 14.72 & 1.10 & 15.60 & 125 & 0.74 & 126.5 & 3.5 & 91.3 & 6.3 & 132.0 & 330 & 0.88 & 5 & 1.4 & 0.3 & 0.12 & 0.02 \\
\hline & 2 & 8.5 & 14.32 & 0.96 & 14.46 & 432 & 0.96 & 121.4 & 5.1 & 80.2 & 11.6 & 127.5 & 456 & 0.85 & 60 & 1.4 & 0.3 & 0.11 & 0.02 \\
\hline & 3 & 11.6 & 4.10 & 0.43 & 5.04 & 271 & 0.76 & 108.5 & 2.6 & 84.5 & 10.0 & 112.8 & 382 & 0.78 & 90 & 1.5 & 0.5 & 0.05 & 0.03 \\
\hline
\end{tabular}

$214 \eta_{\text {end }}$ : Mean ripple height at the end of the experiments.

$215 \lambda_{\text {end }}$ : Mean ripple wavelength at the end of the experiments.

$216 \quad r^{2}$ : Squared correlation coefficient of the best fit curve.

217 SD: Standard deviation. 
a.

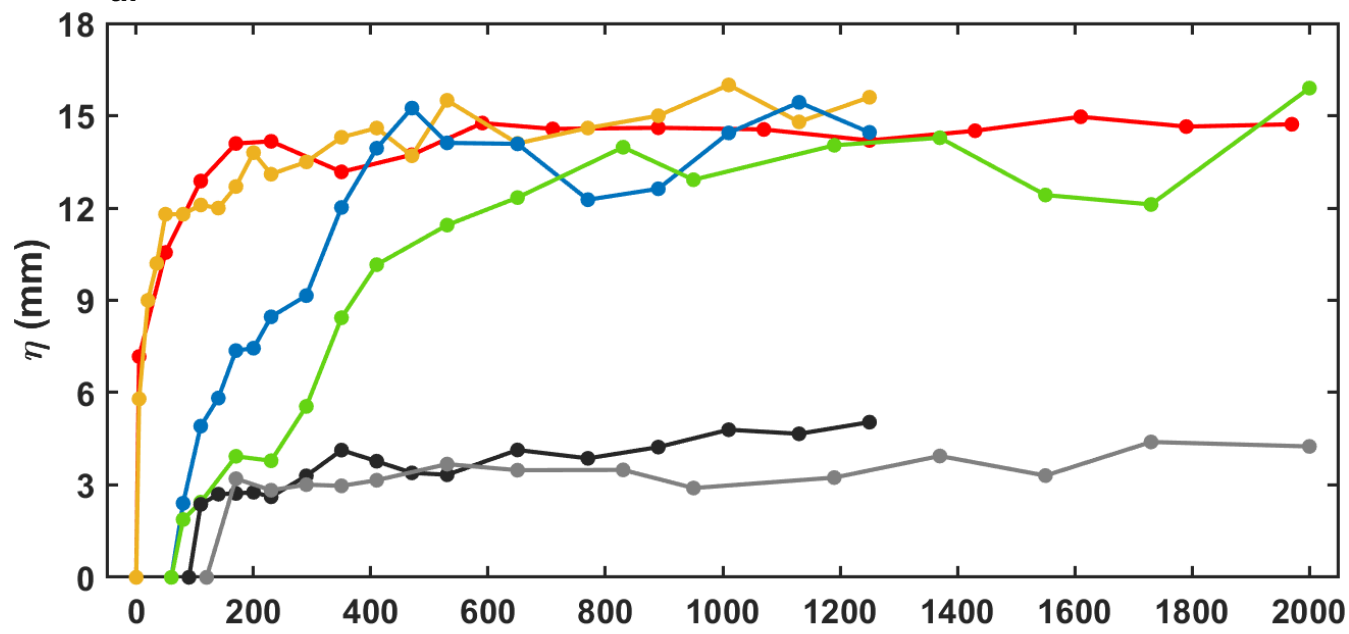

b.

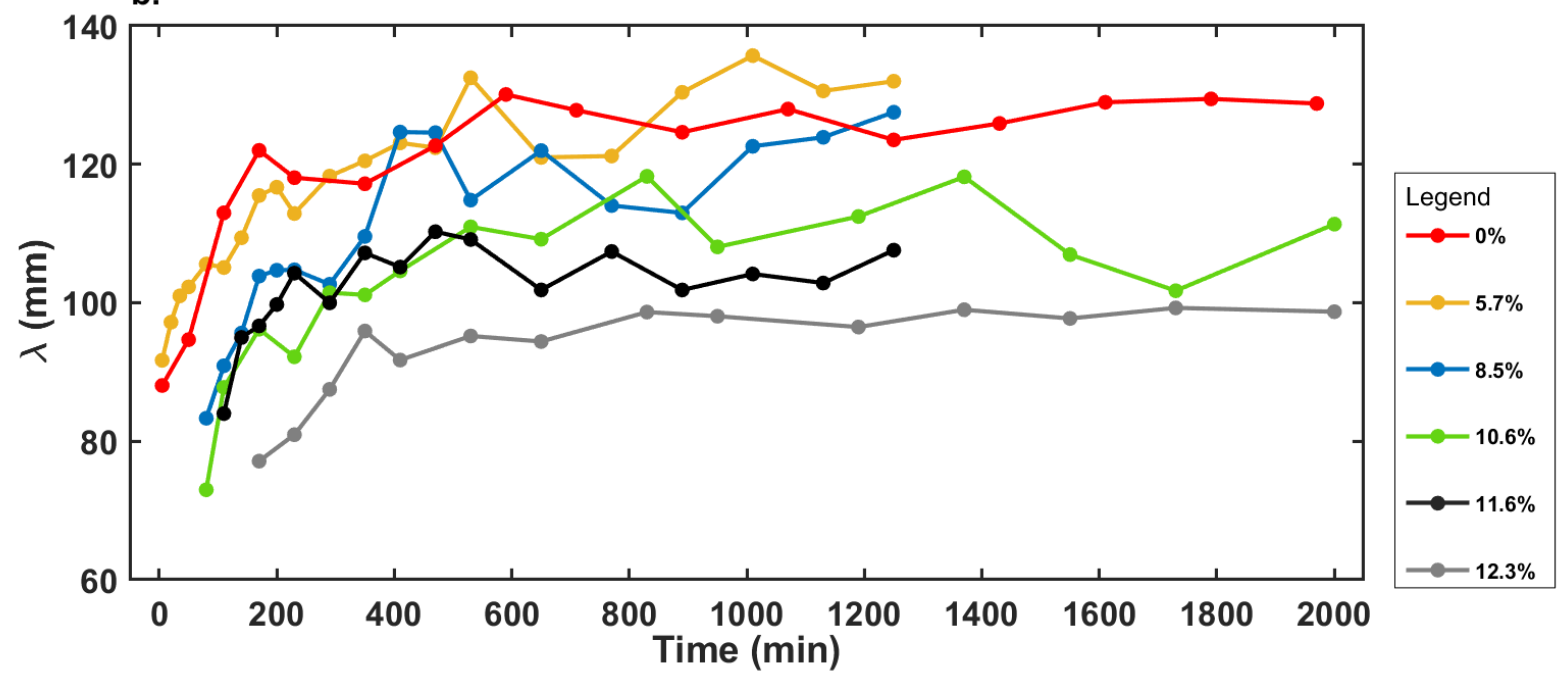



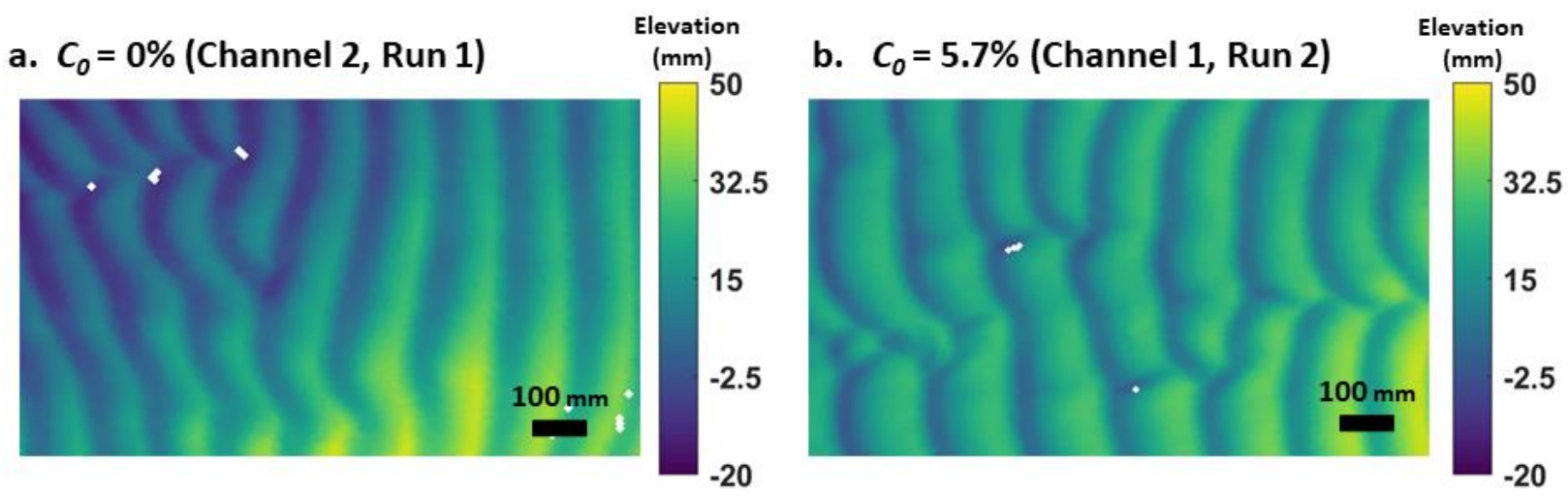

c. $C_{0}=8.5 \%$ (Channel 2, Run 3)

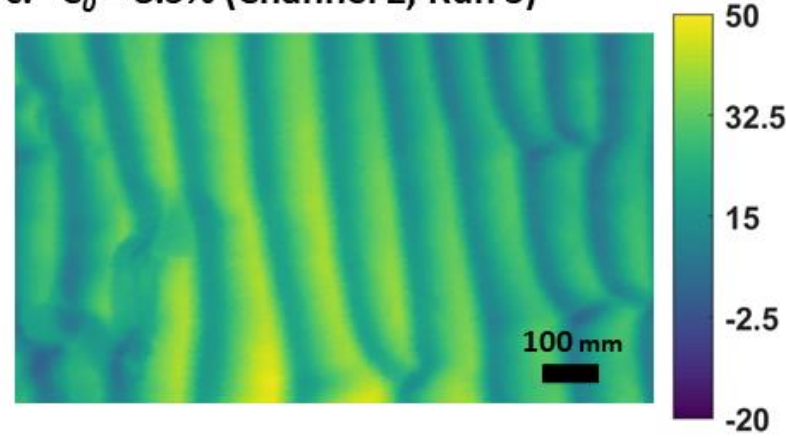

d. $C_{0}=10.6 \%$ (Channel 2, Run 2)

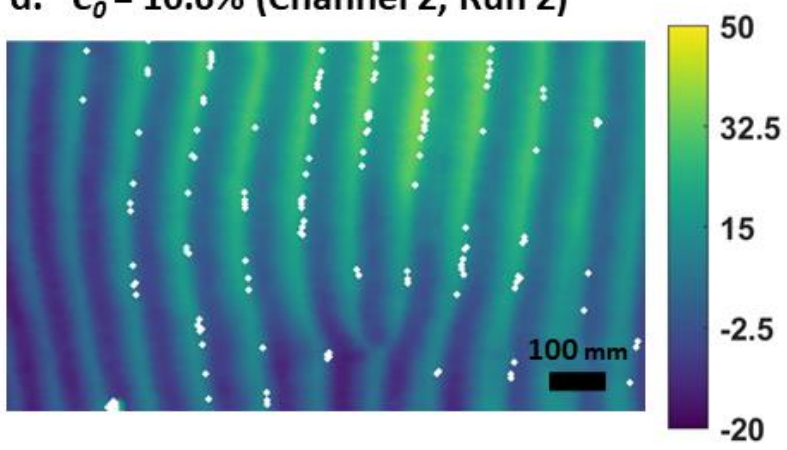

e. $C_{0}=11.6 \%$ (Channel 3, Run 3)

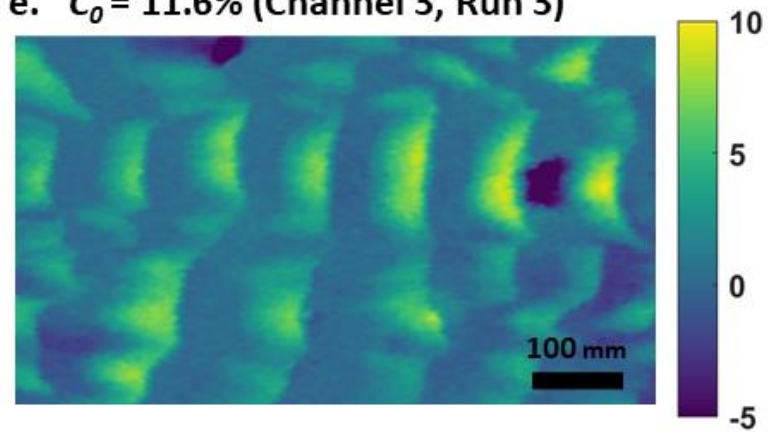

f. $C_{0}=12.3 \%$ (Channel 3, Run 2)

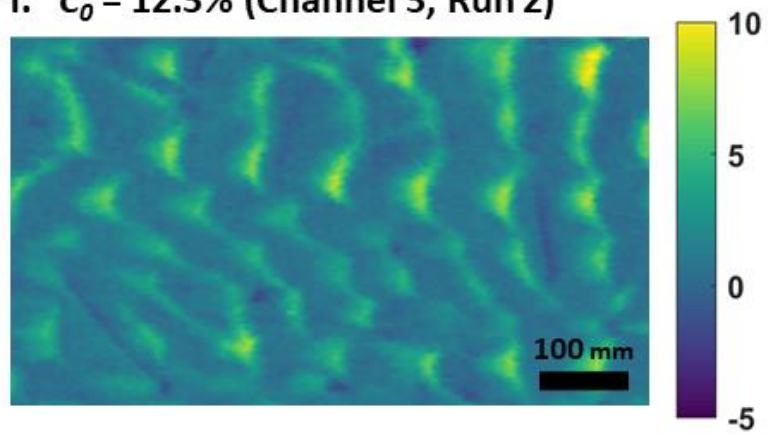

Figure 3. Plan view of the ripple morphology at the end of the experiments in the test section. $C_{0}$ is the initial bed clay content. Note that the colour-scale range in the bottom two panels is different to the rest.

The ripples for the lowest bed clay content, $C_{0}=5.7 \%$ (Run 3, Channel 1), had a similar growth rate to that of the clean-sand ripples in the first $50 \mathrm{~min}$ (Figure 2). Thereafter, the ripple growth rate significantly reduced compared to the counterpart in clean sand, such that it took longer to reach equilibrium: $125 \mathrm{~min}$ for the ripple height and $330 \mathrm{~min}$ for the ripple wavelength. The 
equilibrium dimensions, $\eta_{e}=14.7 \mathrm{~mm}$ and $\lambda_{e}=126.5 \mathrm{~mm}$, were similar to the clean-sand ripples, as was their morphology, with two-dimensional ripples covering the bed (Figure 3b).

As $C_{0}$ was increased, $t_{i}$ increased from $60 \mathrm{~min}$ to $120 \mathrm{~min}$ (Figure 2; Table 2). Increasing the clay content also slowed the subsequent ripple development (Figure 2). This is particularly clear for $C_{0}$ $=10.6 \%$, for which the mean ripple height and wavelength were $3.8 \mathrm{~mm}$ and $92.2 \mathrm{~mm}$ at $t=230$ min, compared to $14.2 \mathrm{~mm}$ and $118.1 \mathrm{~mm}$ for the clean-sand ripples at the same point in time. Thereafter, ripple height experienced a period of relatively rapid, yet gradually decelerating, growth in the following ten hours, reaching $\eta_{t}=10.2 \mathrm{~mm}$ at $t=410 \mathrm{~min}$ and $\eta_{e}=14.2 \mathrm{~mm}$ at $T_{\eta}=$ 834 min (Table 2), which was similar to the equilibrium height of the clean-sand ripples. Ripple wavelength reached equilibrium at $\lambda_{e}=110.8 \mathrm{~mm}$ at $T_{\lambda}=455 \mathrm{~min}$ (Figure 2; Table 2). Not only the dimensions of the ripples were similar to the clean-sand ripples for $C_{0} \leq 10.6 \%$, but these ripples were also two-dimensional, tended to be slightly asymmetrical, with $\mathrm{RSI} \approx 1.3$, and they had RS = 0.11-0.14 (Figure 3c-d; Table 2).

On beds with $11.6 \%$ and $12.3 \%$ clay, the mean ripple height was $2.4 \mathrm{~mm}$ at $t=110 \mathrm{~min}$ and 3.2 $\mathrm{mm}$ at $t=170 \mathrm{~min}$ (Figure 2), followed by periods of weak growth in the remainder of the experiments. At these bed clay contents, the ripples were unable to develop to sizes similar to the clean-sand ripples, reaching $\eta_{e}=4.1 \mathrm{~mm}$ and $\eta_{e}=3.5 \mathrm{~mm}$ at $T_{\eta}=271 \mathrm{~min}$ and $T_{\eta}=211 \mathrm{~min}$, with robust confidence of the best fit curve, $r^{2}=0.78$ and 0.93 , respectively (Table 2 ). These high clay contents also hindered ripple wavelength development. On the bed with $11.6 \%$ clay, 280 min were required to reach $\lambda_{e}=108.5 \mathrm{~mm}$, whereas a longer period of $499 \mathrm{~min}$ was needed to reach a shorter $\lambda_{e}=98 \mathrm{~mm}$ on the bed with $12.3 \%$ clay. These differences in ripple dynamics, compared to the clean-sand ripples, were also reflected in their geometry. For $C_{0}=11.6 \%$, the ripples were quasi2D, characterised by straight but discontinuous crestlines, whereas barchan-shaped ripples with 
252 discontinuous crestlines were observed for $C_{0}=12.3 \%$ (Figure $3 \mathrm{e}-\mathrm{f}$ ). Both these ripple types were

253 more asymmetric, with $\mathrm{RSI}=1.5$, and markedly flatter, with $\mathrm{RS} \approx 0.05$, than the clean-sand ripples

254 (Table 2).

255 Figure 4 illustrates the relationship between the initial clay content and the principal properties of 256 the equilibrium combined-flow ripples. The equilibrium ripple height was almost independent of 257 the initial clay content for $C_{0} \leq 10.6 \%$, at $\eta_{e} \approx 14.4 \mathrm{~mm}$, whereas $\eta_{e}$ collapsed to $3.5 \mathrm{~mm}$ at the 258 highest $C_{0}$ of $12.3 \%$, almost four times smaller than the clean-sand equilibrium height (Figure 4a). 259 The equilibrium wavelength was between $121.4 \mathrm{~mm}$ and $129.1 \mathrm{~mm}$ for $C_{0} \leq 8.5 \%$, and declined 260 linearly at higher $C_{0}$ values, i.e., from $110.8 \mathrm{~mm}$ at $10.6 \%$ to $98 \mathrm{~mm}$ at $12.3 \%$ (Figure $4 \mathrm{~b}$ ). The 261 mean growth rate decreased gradually between $0 \%$ and $12.3 \%$ clay (Figure $4 \mathrm{c}, \mathrm{d}$ ). In the clean262 sand run, $r_{\eta}$ and $r_{\lambda}$, were $0.003 \mathrm{~mm} / \mathrm{s}$ and $0.004 \mathrm{~mm} / \mathrm{s}$, respectively. At $C_{0}=12.3 \%$, the mean 263 growth rates were up to an order of magnitude lower at $r_{\eta}=0.0003 \mathrm{~mm} / \mathrm{s}$ and $r_{\lambda}=0.0006 \mathrm{~mm} / \mathrm{s}$. 
a.

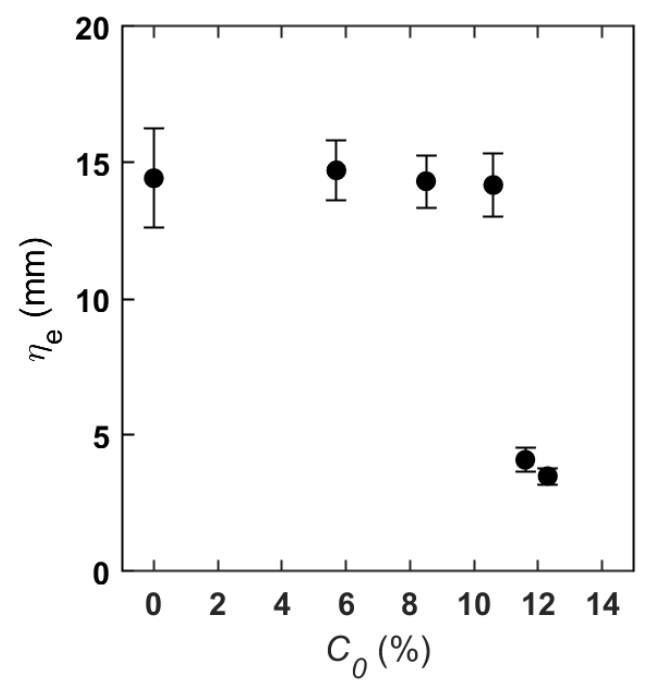

c.

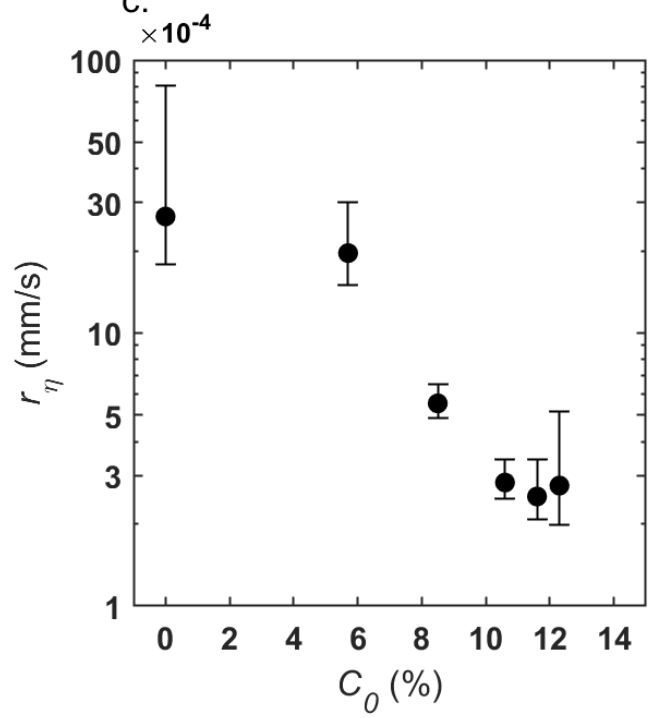

b.

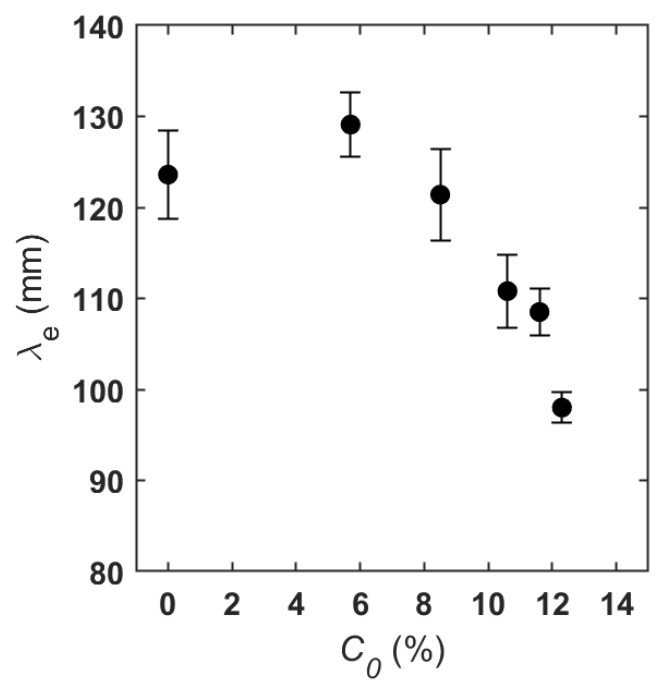

d.

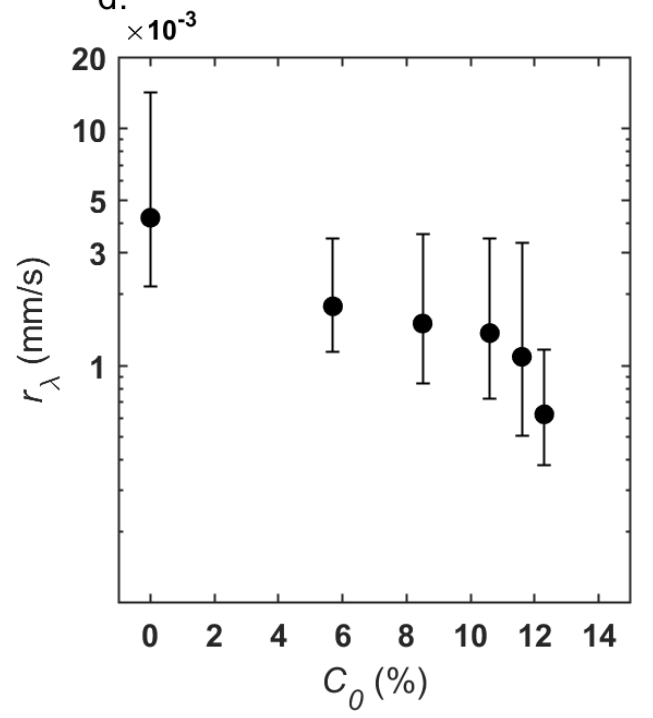

Figure 4. Equilibrium combined-flow (a) ripple height and (b) wavelength, and development rate of (c) ripple height and (d) wavelength against initial bed clay content for all experiments. Black bars denote $95 \%$ confidence intervals, derived 3.2. Change in bed clay content with ripple development

270 Figure 5 shows representative examples of the changes in bed clay content for different stages in 271 the development of the ripples at $C_{0}=5.7 \%, 10.6 \%$, and $12.3 \%$, based on the grain-size analysis 272 of the sediment in the cores. The first profile for $C_{0}=5.7 \%$ was at $t=5 \mathrm{~min}$, when the bed was 
273 partly flat and partly occupied by small ripples. In the upper $15 \mathrm{~mm}$ of the flat bed core (black line 274 in Figure 5a), the clay content was about half of its initial value (grey vertical solid line in Figure 275 5a). Below this layer, the clay content increased with depth to its initial value (Figure 5a). The 276 sand was free of clay below the crest of the small, $8 \mathrm{~mm}$ high, ripples, whereas a small amount of 277 clay remained at the base of the ripple (blue line in Figure 5a). In a 10-mm thick layer immediately 278 below the ripple trough, the clay content was c. $60 \%$ lower than the initial value (red line in Figure 279 5a). Below this layer, the clay content had remained close to its initial value (Figure 5a). Figures $2805 \mathrm{~b}-\mathrm{e}$ illustrate the effect of ripple growth on bed clay content. The clay content in the rippled part 281 of the cores was zero, indicating that the winnowing of clay from the bed kept pace with the growth 282 in ripple height. Furthermore, the thickness of the layer losing clay just below the ripple base 283 progressively expanded downwards until it reached the pre-experiment value at the base of the 284 deposit between $650 \mathrm{~min}$ and $1250 \mathrm{~min}$. 

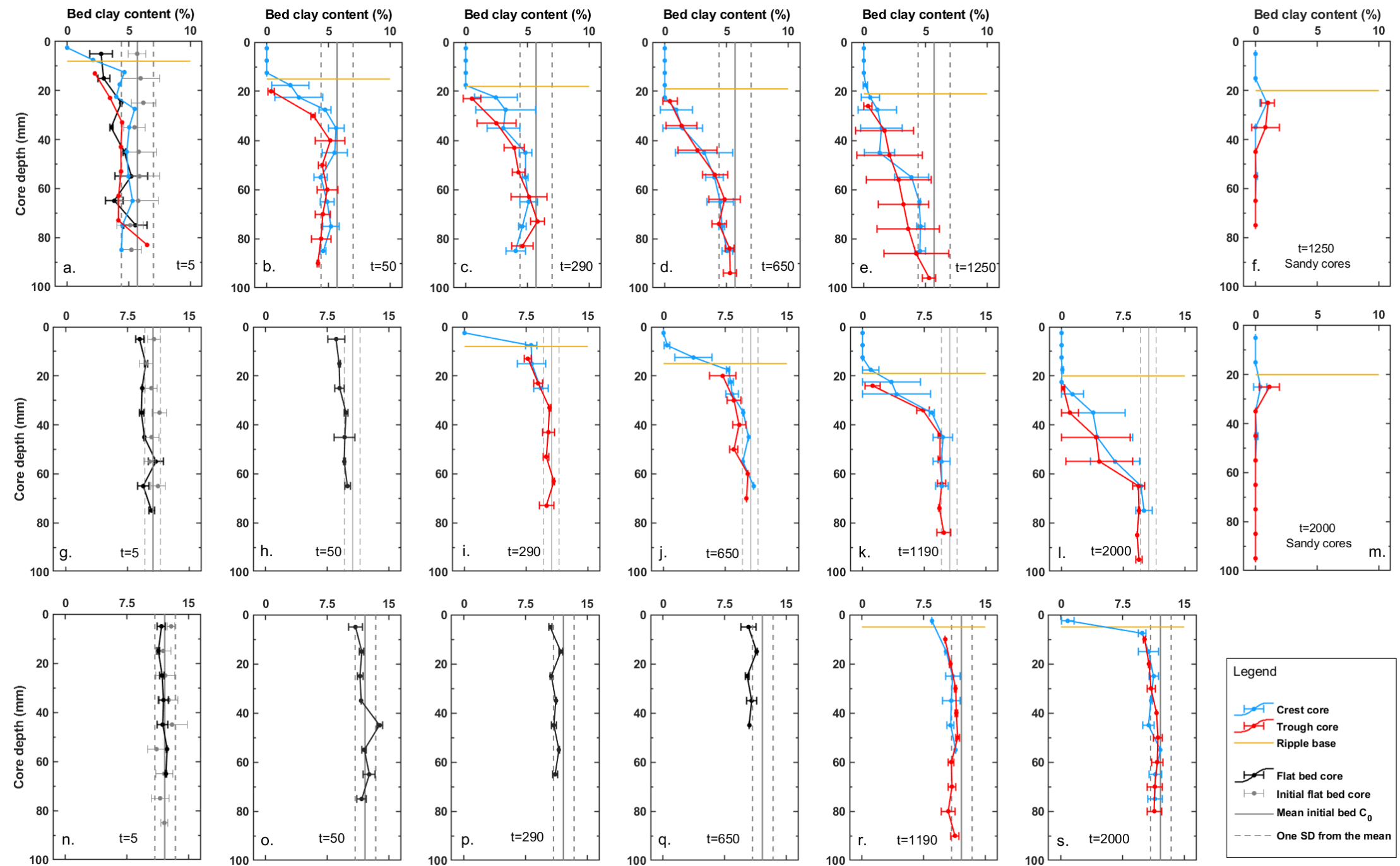

Figure 5. Vertical profiles of clay content in cores collected from beds in the mixed sand-clay section with clay content of 

vertical solid lines and the vertical dash lines represent mean initial clay content and one standard deviation of the mean. The black, blue, and red dots denote mean clay content below the active flat bed, ripple crest, and ripple trough, respectively. The black, blue, and red horizontal bars denote one standard deviation of mean clay content. The yellow 
Five minutes after the start of the run with $C_{0}=10.6 \%$, the clay content in the top $10 \mathrm{~mm}$ of the flat bed core was lower than the initial value, but above $7.5 \%$; this layer of slightly reduced clay content had expanded downward to c. $30 \mathrm{~mm}$ at $t=50 \mathrm{~min}$ (Figure $5 \mathrm{~g}, \mathrm{~h}$ ). By $t=290 \mathrm{~min}$, the ripples contained $100 \%$ sand just below the ripple crest. Akin to the $5.7 \%$ clay run, clay was retained at the ripple base, with a $\sim 10 \mathrm{~mm}$ thick layer showing a c. $30 \%$ reduction in clay content underneath the ripples (Figure 5i). Compared to $C_{0}=5.7 \%$, the sediment cores demonstrate a slower evolution towards fully developed sandy ripples in conjunction with a slower downward expansion of the layer with reduced clay content underneath the ripples (Figure $5 i-1)$. Figures $5 f$ and $5 \mathrm{~m}$ show vertical profiles of bed clay content collected from ripples in the downstream clean sand section at the end of the experiments. Both profiles reveal clay-free ripples and a clayenriched layer below the base of the ripples. This layer was c. $20 \mathrm{~mm}$ thick at $C_{0}=5.7 \%$ and c. 10 mm thick at $C_{0}=10.6 \%$.

The bed clay content in the run with $C_{0}=12.3 \%$ was close to the initial value at $t=5$ min (Figure 306 5n). At $t=50 \mathrm{~min}$, the upper $10 \mathrm{~mm}$ of the bed had lost a small amount of clay; ripples had not formed at this stage (Figure 5o). Tiny ripples were present at $t=290 \mathrm{~min}$ and $t=650 \mathrm{~min}$, but it was not possible to sample through the crests and troughs of these ripples. Bed clay content in the upper $10 \mathrm{~mm}$ had continued to decrease at these times (Figure 5p, q). Draining the tank at $t=1190$ min and $t=2000$ min revealed small, c. $5 \mathrm{~mm}$ high, ripples. These ripples had retained $8.5 \%$ clay at $t=1190 \mathrm{~min}$, but only $0.8 \%$ at $t=2000 \mathrm{~min}$. Again, a thin layer of reduced clay content was present just below the base of the ripples, in which the clay content gradually recovered downward to its initial value, but the initial value was reached at shallower depths than in the runs with lower initial bed clay content (Figure 5r, s). 


\section{Discussion}

317 4.1. Ripple Development on Cohesive Substrates under Combined Flows

318 The experimental results described in this paper illustrate the role of cohesive sediment in changing

319 the dynamics of combined-flow ripples by slowing the ripple growth rate (Figure 4c, d; cf. Baas

320 et al., 2013; Wu et al., 2018). For beds with $C_{0} \leq 10.6 \%$, the ripples developed to a comparable

321 equilibrium shape and size, with $\eta_{e} \approx 14.4 \mathrm{~mm}$ and $\lambda_{e} \approx 123.8 \mathrm{~mm}$, but the cohesive forces caused

322 the equilibrium time to increase exponentially as $C_{0}$ was increased from $0 \%$ to $10.6 \%$ (Table 2 ).

323 These observations are consistent with the findings of $\mathrm{Wu}$ et al. (2018), who studied the

324 development of wave ripples on sand beds with up to 7.4\% kaolinite clay. However, Baas et al.

325 (2013) described a small decrease in height and a constant wavelength of current ripples, as $C_{0}$

was increased from $0 \%$ to $12.6 \%$, and Baas et al. (2013) found a similar equilibrium time for all ripples independent of bed kaolinite content. The relatively short duration of 2 hours used in the experiments of Baas et al. (2013) may have prevented the best-fit equations (cf. Equations 3 and

4) from predicting sufficiently accurate equilibrium times, especially at $C_{0}$ values between $7 \%$ and 12.6\%. This viewpoint is supported by the experiments with mixtures of sand and biologically cohesive extracellular polymetric substances (EPS) of Malarkey et al. (2015), whose flow and sand properties were similar to those of Baas et al. (2013), but their runs lasted between 4 and 73 hours. Malarkey et al. (2015) concluded that current ripples developing on beds with EPS contents ranging from $0.016 \%$ to $0.125 \%$ reached similar equilibrium size and geometry as EPS-free current ripples, provided that sufficient time was allowed for their formation.

336 The two strongest levels of bed cohesion $\left(C_{0}=11.6 \%\right.$ and $\left.12.3 \%\right)$ used herein not only led to 337 greatly reduced ripple dimensions $\left(\eta_{e}<5 \mathrm{~mm}, \lambda_{e}<108 \mathrm{~mm}\right)$, but also to significantly different 338 ripple geometries. At $\mathrm{RS}=0.04$, these small ripples resemble rolling-grain ripples without flow 
separation at the crest, as opposed to vortex ripples with flow separation that require RS $>0.1$ (Miller and Komar, 1980). Rolling-grain ripples are associated with steady circulation cells on either side of the ripple crest (Hara and Mei, 1990), which drive sediment towards the crest, causing the ripple to grow until it is steep enough for flow separation and periodic vortex shedding to begin (e.g., van der Werf et al., 2008). Perillo et al. (2014b) identified small and twodimensional rolling-grain ripples on clean sand beds under combined flows. However, the rollinggrain ripples at $C_{0}=12.3 \%$ in the present study were barchan-shaped (Figure $3 \mathrm{f}$ ). It is likely that the stronger cohesion within the bed at $C_{0}=12.3 \%$ prevented these ripples from evolving into the two-dimensional ripples with discontinuous crestlines of $C_{0}=11.6 \%$ or even the straight-crested and continuous ripple trains of $C_{0} \leq 10.6 \%$.

Previous experiments have found that clean-sand rolling-grain ripples are a transitional and unstable stage towards equilibrium vortex ripples (Scherer et al., 1999, Stegner and Wesfreid, 1999, Faraci and Foti, 2001). This transition is usually a rapid process. In the clean-sand experiments of Faraci and Foti (2001), rolling-grain ripples lasted less than 240 seconds before developing into vortex ripples at $U_{o}=0.43 \mathrm{~m} / \mathrm{s}$. In our experiments, however, the rolling-grain ripples were stable for over 20 hours (Figure 2). We therefore infer that an equilibrium state - or at least a prolonged metastable state - for these ripples is possible in mixed sand-clay. The sudden increase in physical cohesion in the bed as increasing $C_{0}$ may have limited the supply of sand from below the base of the ripples, thus keeping the ripples small enough to become fixed in the rollinggrain ripple stage. Faraci and Foti (2001) demonstrated a short transient period of stalling in the growth of rolling-grain ripple height towards vortex ripples. A similar but much longer period of stalling was observed at $C_{0}=10.6 \%$ in the present experiments; the ripple height remained at c. 4 $\mathrm{mm}$ at $170<t<230 \mathrm{~min}$, followed by continued growth towards equilibrium when the clay content 
362 immediately below the ripple troughs decreased below 8\% (Figure 2; Figure 5i). A clay content of $3638 \%$ may therefore be a threshold below which growth towards the equilibrium size typical of clean364 sand ripples is able to occur, and ripples develop separation eddies typical of vortex ripples. Bed 365 clay content above $8 \%$ thus prevent the circulation cells from supplying enough sand from the 366 troughs to allow the ripples to grow and the flow to separate, so the rolling-grain ripples persist. 367 This threshold was never passed in $12.3 \%$ clay run, since the clay content below the base of the 368 ripples remained at $10 \%$ or above consistently (Figure 5r, s), resulting in the persistence of rolling369 grain ripples until the end of the experiment. Further research designed to quantify the clay-content

threshold for the change from rolling-grain to vortex ripples under different forcing conditions is required to fully understand the influence of cohesive clay on ripple evolution and equilibrium ripple size and shape. Interestingly, Baas et al. (2013) also found a drastic reduction in the size of current ripples in runs with over $13 \%$ bed clay, with heights and wavelengths lower than $5.5 \mathrm{~mm}$ and $80 \mathrm{~mm}$. These ripples were two-dimensional and flatter than the three-dimensional, linguoid, equilibrium clean-sand ripples $(\mathrm{RS} \approx 0.05$ versus $\mathrm{RS} \approx 0.13$; Baas et al., 2013). Most significantly, once formed these small current ripples were stable until the end of the experiments.

It is therefore concluded that two distinct types of equilibrium wave, current, and combined flow ripples are able to develop on mixed sand-clay beds, with the conceptual models of these two types of ripple development shown inFigure 6. If $C_{0}$ is lower than the threshold bed clay concentration, $C_{t}$, relatively large equilibrium ripples, with dimensions and geometries comparable to clean-sand counterparts, are developed. These ripples experience similar development stages as those of clean-sand ripples, including incipient, growing, and equilibrium stages (Perillo et al., 2014b; Figure $6 a-d)$, although the growth rate is lower than that of the clean-sand ripples. Relatively small and flat equilibrium ripples are generated as $C_{0}>C_{t}$ (Figure $6 \mathrm{e}-\mathrm{h}$ ). Incipient 
385 ripples that appear after an extended period of flat bed conditions because of high bed cohesion, 386 are unable to grow to large sizes because of a lack of sand supply from below (Figure $6 \mathrm{~g}-\mathrm{h}$ ). 


\section{$C_{0}<C_{t}$}

a. Flat bed

Flow direction

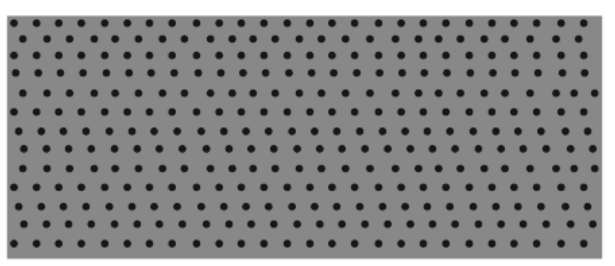

\section{b. Incipient stage}

- Small dimensions

- Clean-sand below the small ripple crest

- Clay remained in the ripple base

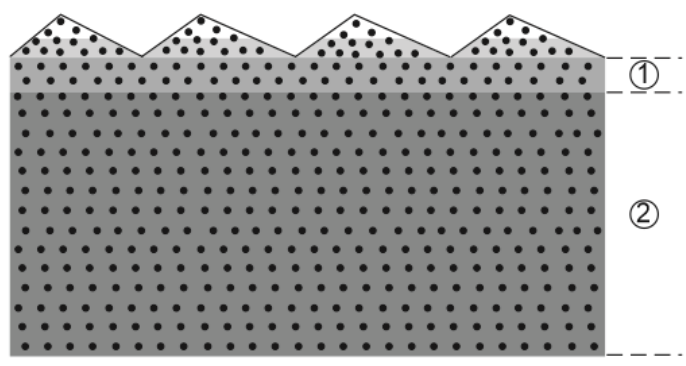

\section{c. Growing stage}

- Growth rate decreases with increasing $C_{0}$

- Evolution to sandy ripples

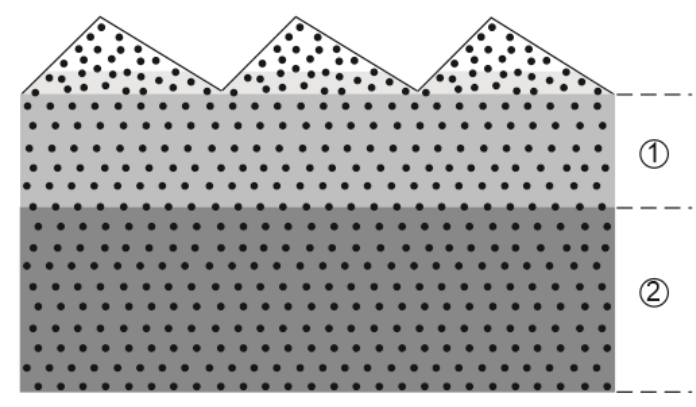

\section{d. Equilibrium stage}

- Clean-sand ripples

- Similar dimensions and geometries as ripples from clean-sand bed

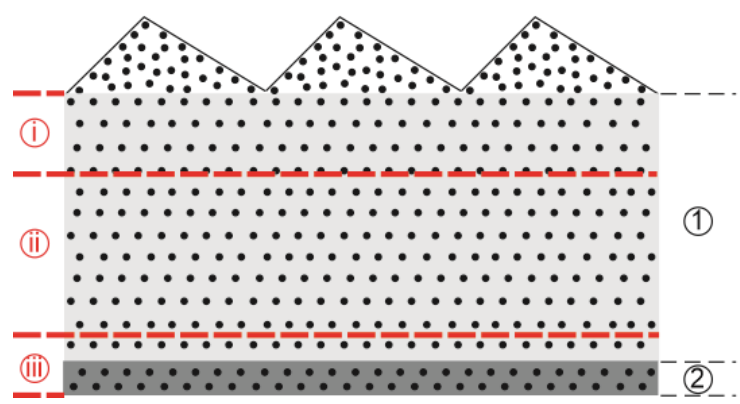

$C_{0}>C_{t}$

e. Flat bed
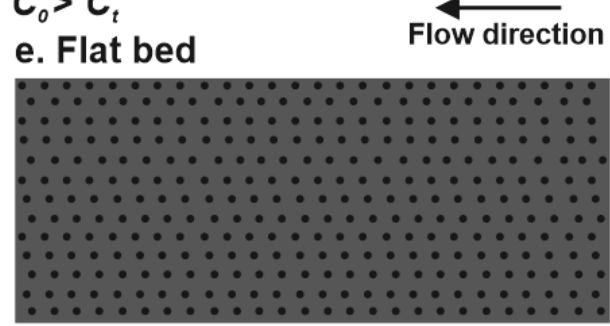

\section{f. Bed remains nearly flat}

- High bed cohesion to resist bed erosion

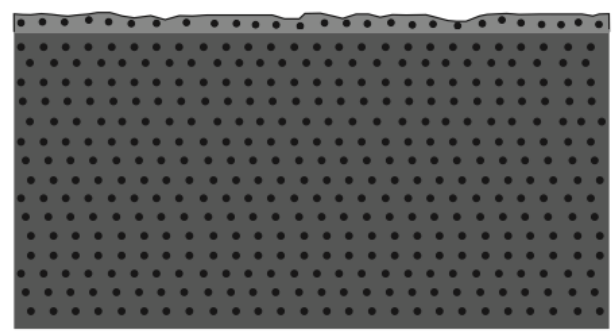

\section{g. Incipient stage}

- Small and flat ripples within relatively high clay content

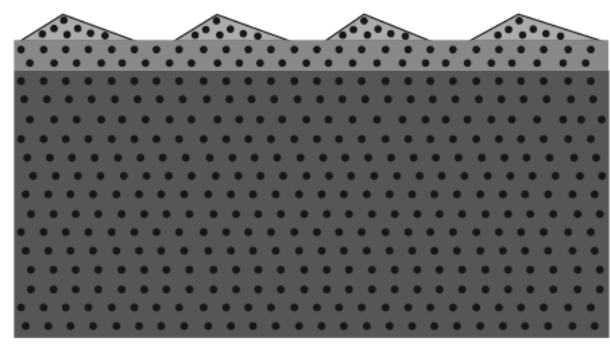

\section{h. Equilibrium stage}

- Small and flat ripples within small amount of clay

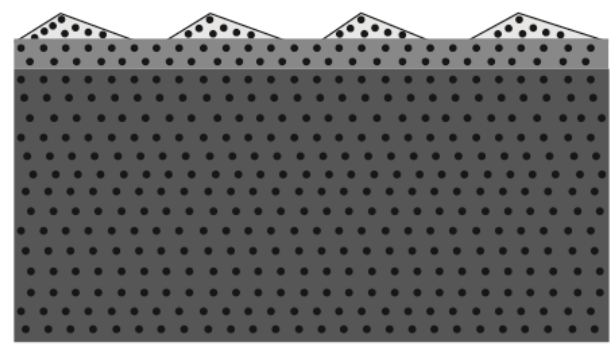

(1) and (2): clay loss and inactive layer below combined-flow ripples

(i), (iii, and (iii) : clay loss, clay-enriched, and inactive layer below wave ripples (Wu et al., 2018) 
Figure 6. Conceptual models showing the development stages of (a - d) large and (e - f) small equilibrium ripples under currents, waves, and combined flows. $C_{t}$ : threshold bed clay content. The horizons with different clay fractions are presented by different shades of grey. Red dash lines represent boundaries of sediment layers below the wave ripples of $\mathrm{Wu}$ et al. (2018).

\subsection{Influence of Clay Winnowing on Ripple Development}

The present experiments, as well as previous flume studies (e.g., Malarkey et al., 2015, Wu et al., 2018), indicate that the equilibrium dimensions of ripples on weakly cohesive, mixed sand-clay beds are similar to those of their clean-sand equivalents, but that these ripples may take an exponentially longer time to reach equilibrium than clean-sand ripples. Our core data confirm earlier findings that winnowing of fine, cohesive material, i.e., clay and EPS, from the active surficial sediment layer leads the transformation of a cohesive bed to sandy ripples (Baas et al. 2013; Wu et al., 2018). During winnowing, small clay particles (and EPS) are preferentially resuspended from the bed because of their low critical entrainment velocity (Allan and Frostick, 1999). Winnowing therefore plays a significant role in bed coarsening (Blom et al., 2003, Liang et al., 2007). Winnowing of clay occurs preferentially by hyporheic flow below ripple troughs (Blom et al., 2003), thus supplying sand from underneath the base level of ripples to assist ripple growth. However, hyporheic flows, and therefore winnowing, can get blocked when the bed clay content is sufficiently high to fill the pore space (Niño et al., 2003, Staudt et al., 2017). In the present experiments, the increase in bed clay content from $5.7 \%$ to $12.3 \%$ is inferred to have caused a progressive decrease in the rate of winnowing of clay by hyporheic flow, in combination with a progressive increase of critical bed shear stress for sediment motion with increasing bed clay content (e.g., Panagiotopoulos et al., 1997). Hence, the ripple growth rate decreased with 
411 increasing bed clay content, because the rate of clay winnowing decreased, in turn leading to a 412 reduced supply of sand needed for ripple growth.

$413 \mathrm{Wu}$ et al. (2018) recognised layers enriched in clay relative to initial bed clay content below 414 equilibrium wave ripples (Figure 6d). The sediment below the combined-flow ripples in our cores 415 did not record such layers, with clay loss layers instead dominating sedimentary texture during 416 ripple development (Figure $6 \mathrm{a}-\mathrm{d}$ ). However, clay did accumulate between 25 and $35 \mathrm{~mm}$ in the 417 sandy section downstream of the mixed sand-clay beds (Figure $5 \mathrm{f}, \mathrm{m}$ ). This provides further 418 evidence that suspended clay can be carried into rippled beds by hyporheic flow, driven by pressure 419 gradients between ripple troughs and crests (e.g., Huettel et al., 1996, Karwan and Saiers, 2012, Wu et al., 2018, Dallmann et al., 2020). Clay probably also entered the rippled beds in the mixed 421 sand-clay test section, as evidenced by plateaus of increased clay content immediately below the ripple base, e.g., between 22.5 and $45 \mathrm{~mm}$ and between 35 and $55 \mathrm{~mm}$ at the end of Runs 3 and 2, respectively (Figure 5e, 1). These depths are similar to the depths at which clay accumulated in the downstream sandy area and in the wave-ripple experiments of $\mathrm{Wu}$ et al. (2018; their figure 11). There therefore appears to be a dynamic balance between clay loss and gain below the base of the ripples. Clay gain by downward movement was higher than clay loss by upward winnowing below the base of the wave ripples, causing net clay accumulation at this depth, whereas winnowinginduced clay loss was dominant in the present combined-flow experiments, thus causing 'deep cleaning' of bed clay (Figure 6d). This suggests that winnowing was stronger under the combined430 flow forcing herein than under the pure wave forcing of $\mathrm{Wu}$ et al. (2018). Currents with 431 superimposed waves are well known to generate high turbulence intensities and shear stresses in 432 the wave boundary layer, resulting in apparent bed roughness lengths that are much greater than 433 the sum of their constituents (Grant and Madsen, 1979, Mathisen and Madsen, 1996). Indeed, 
434 based on the Malarkey and Davies (2012) shear stress calculation method, the maximum skin

435 friction shear stress in the present experiments was $1.41 \mathrm{~Pa}, \mathrm{c} .40 \%$ higher than under the pure 436 wave conditions with similar free-stream maximum orbital velocities of Wu et al. (2018). Hence, 437 combined flow has the capacity to induce stronger forces to winnow more clay from rippled mixed 438 sand-clay beds than pure oscillatory flow. Moreover, hydrodynamic forces control hyporheic 439 flows through the bed, i.e., pore water velocity scales positively with flow velocity (Elliott and 440 Brooks, 1997, Karwan and Saiers, 2012). Clark et al. (2019) highlighted that combined flow 441 produced a deeper hyporheic exchange than that induced by currents alone due to 'wave pumping' 442 effect. Furthermore, Packman et al. (2000) developed a method for the calculation of pore water 443 velocity, $u_{p}$, in a rippled bed:

$$
u_{p}=k K h_{m}
$$

where $k=2 \pi / \lambda$ is the hydraulic conductivity, $K=600 D_{10}^{2}, D_{10}$ is the 10 -precentile of the grain446 size distribution, $h_{m}=0.14\left(U^{2} / \mathrm{g}\right)(\eta / 0.34 h)^{3 / 8}$ is the half-amplitude dynamic head, $\mathrm{g}$ is gravitational 447 acceleration, and $U$ is the root-mean square flow velocity (Precht and Huettel, 2003). For $U=0.31$ $448 \mathrm{~m} / \mathrm{s}$ and $D_{10}=0.3 \mathrm{~mm}$ in the present experiments, $u_{p}=1.5 \mathrm{~mm} / \mathrm{min}$, whereas the pore water 449 velocity was $40 \%$ lower, i.e., $u_{p}=0.9 \mathrm{~mm} / \mathrm{min}$, in the pure-wave experiments of Wu et al. (2018). 450 This higher pore water velocity, combined with the higher bed shear stress, may explain why the 451 clay can be winnowed from deeper levels in the substrate under combined-flow forcing.

\subsection{Implications for Natural Environments}

453 The present experiments, supported by Baas et al. (2013) and Wu et al. (2018), show that ripple 454 types change into one another across a narrow range of bed clay contents, suggesting a 455 discontinuity in ripple dimensions and geometries that is not incorporated in mathematical 
predictors for bedform height and wavelength (e.g., Tanaka et al., 1996; Nelson et al., 2013). Because the large equilibrium ripples resemble clean-sand ripples as a result of highly effective clay winnowing, the application of these predictors may be extended from pure sand beds to weakly cohesive mixed sand-clay beds. However, these predictors need to be modified to capture the small equilibrium ripples that are stable only on strongly cohesive beds. This indicates that bedform predictors developed from clean-sand ripples are likely to overpredict ripple roughness for sand beds with a high bed clay content. Indeed, using $k_{s}=27.7 \eta^{2} / \lambda(\mathrm{Li}$ and Amos, 1998), where $k_{s}$ is the bed roughness due to form drag, the sudden reduction in ripple dimensions at $C_{0} \approx 11 \%$ (Figure $4 a, b$ ) causes the bed roughness to decrease by an order of magnitude. Brakenhoff et al. (2020) highlighted the fact that small changes in predicted form roughness could result in large changes in sediment transport rate predictions. The data in this study show that such errors may result from neglecting the profound effect of cohesive forces in mixed sand-clay beds, thus limiting the ability of models to accurately predict changes in the bed morphology of estuaries and coastal sea. The discontinuity between large and small combined-flow ripples was at an initial bed clay content of $11 \%$ and at a clay content of c. $8 \%$ below the base of the ripples. It is expected that these threshold concentrations depend on the maximum combined shear stress, which in nature can be significantly higher than in the present experiments. For example, strong bed shear stresses during extreme weather events might increase the threshold bed clay content below which bedforms in mixed sand-clay beds can attain the size of clean-sand equivalents through clay winnowing. On the other hand, EPS-induced biological cohesion in sediment has a stronger capacity to resist erosion compared to physical cohesion; small proportions of EPS, of the order of $0.1 \%$, are highly effective in hindering bedform evolution (Malarkey et al., 2015, Parsons et al., 2016). This should reduce the cohesion threshold for clean-sand equivalent bedform development 
479 in mixed sand-clay-EPS sediment beds in nature and work against the increase in this threshold 480 as a result of the higher bed shear stresses described above. The findings in this paper should act as a stimulus for further studies towards fully quantifying changes in ripple morphology as a 482 function of hydrodynamic forcing and bed cohesion. This would also be helpful for designing the next-generation phase diagrams for combined-flow bedforms, which at present do not cover bed 484 cohesion and therefore cannot predict the small equilibrium ripples found in this study (Dumas et al., 2005, Perillo et al., 2014a). change from a cohesive substrate to a mobile, predominantly sandy substrate is likely to occur also further challenge the modelling of sediment transport in estuaries, given that river flooding often goes hand in hand with storm events (e.g., Gong et al., 2007, Ralston et al., 2013). Such combined flows would not only lead to clay loss by winnowing under high maximum bed shear stress, but it may also lead to an increased supply into the estuary of suspended terrestrial clay as well as organic over a short amount of time, with potentially severe impacts on the health of the estuarine environment. For example, a sudden, large release of nutrients may cause algal blooms ('red tides'; Brand et al., 2012), and a sudden, large release of contaminants causes near-instantaneous 
water pollution, threatening the ecological balance of estuarine and coastal environments and anthropogenic activities. The findings of this study are therefore also beneficial for the development of evidence-based water-quality regulations in estuaries.

\section{Conclusions}

Our experiments examined the importance of physical cohesion on the size and morphology of ripples generated by combined waves and currents. The experimental data illustrate that, with initial clay content, $C_{0}$, increasing from $0 \%$ to $12.3 \%$, ripple height and wavelength development rates, $r_{\eta}$ and $r_{\lambda}$ decreased one order of magnitude from $0.003 \mathrm{~mm} / \mathrm{s}$ to $0.0003 \mathrm{~mm} / \mathrm{s}$ and from 0.004 $\mathrm{mm} / \mathrm{s}$ to $0.0006 \mathrm{~mm} / \mathrm{s}$, respectively. Importantly, the experimental results also revealed the development of two distinct types of equilibrium ripples on mixed sand-clay beds. For $C_{0} \leq$ $10.6 \%$, large two-dimensional, quasi-asymmetrical equilibrium ripples developed, with equilibrium height and wavelength, $\eta_{e} \approx 14.4 \mathrm{~mm}, \lambda_{e} \approx 123.9 \mathrm{~mm}$, ripple symmetry index, RSI $\approx$ 1.4 , and ripple steepness, $\mathrm{RS} \approx 0.12$. These geometric values are close to those of clean-sand ripples, because the winnowing of clay from the developing ripples at these low $C_{0}$-values was highly effective - typically amounting to $100 \%$ clay loss — and clay winnowing extended far below the ripples during equilibrium bed morphology. This 'deep cleaning' of clay is probably attributable to higher bed shear stresses and pore water velocities under combined flow than under pure currents and pure waves. In contrast, high bed cohesion at $C_{0}>11 \%$ led to a discontinuity in equilibrium ripple height, generating small, flat, and more asymmetrical equilibrium ripples, with $\eta_{e}$ and RS collapsing to $\sim 4 \mathrm{~mm}$ and 0.04 , respectively, but RSI increasing to 1.5 . This discontinuity is explained by a sudden increase in bed cohesion as a function of increasing bed clay content, 
523 which prevents the erosion of ripple troughs and limits the sand supply needed for the growth

524 towards the larger combined-flow ripples.

\section{Acknowledgments}

526 The authors acknowledge the enormous contributions of Brendan Murphy, whose help throughout 527 the study made our setup, data collection, and clean-up efforts smooth and trouble-free. We also 528 acknowledge the extremely useful contributions of Ellen Pollard, Dr. Hachem Kassem, Prof. Stuart 529 McLelland, Dr. Elena Bastianon, Dr. Anne Baar, Dr. Christina Roggatz, and Sojiro Fukuda during 530 different stages of the experiments. Participation of XW, RF, JM and DP was made possible thanks 531 to funding by the European Research Council under the European Union's Horizon 2020 research 532 and innovation program (grant 725955). Participation of RF also supported by the Leverhulme

533 Trust, Leverhulme Early Career Researcher Fellowship (grant ECF-2020-679).

\section{Conflict of Interest}

535 The authors declare no conflicts of interest relevant to this study.

Open Research

538 Supporting data (Wu et al., 2021) are available through figshare under the following link:

539 doi.org/10.6084/m9.figshare.16715578.v1. 


\section{References}

Allan, A. F. \& Frostick, L. 1999. Framework dilation, winnowing, and matrix particle size; the behavior of some sand-gravel mixtures in a laboratory flume. Journal of Sedimentary Research, 69, 21-26.

Baas, J. H. 1994. A flume study on the development and equilibrium morphology of current ripples in very fine sand. Sedimentology, 41, 185-209.

Baas, J. H. 1999. An empirical model for the development and equilibrium morphology of current ripples in fine sand. Sedimentology, 46, 123-138.

Baas, J. H., Baker, M. L., Malarkey, J., Bass, S. J., Manning, A. J., Hope, J. A., Peakall, J., Lichtman, I. D., Ye, L. \& Davies, A. G. 2019. Integrating field and laboratory approaches for ripple development in mixed sand-clay-EPS. Sedimentology, 66, 2749-2768.

Baas, J. H., Davies, A. G. \& Malarkey, J. 2013. Bedform development in mixed sand-mud: The contrasting role of cohesive forces in flow and bed. Geomorphology, 182, 19-32.

Blom, A., Ribberink, J. S. \& De Vriend, H. J. 2003. Vertical sorting in bed forms: Flume experiments with a natural and a trimodal sediment mixture. Water Resources Research, 39.

Brakenhoff, L., Schrijvershof, R., Van Der Werf, J., Grasmeijer, B., Ruessink, G. \& Van Der Vegt, M. 2020. From ripples to large-scale sand transport: The effects of bedform-related roughness on hydrodynamics and sediment transport patterns in delft3d. Journal of Marine Science and Engineering, 8, 892.

Brand, L. E., Campbell, L. \& Bresnan, E. 2012. Karenia: The biology and ecology of a toxic genus. Harmful algae, 14, 156-178. 
Cizeau, P., Makse, H. A. \& Stanley, H. E. 1999. Mechanisms of granular spontaneous stratification and segregation in two-dimensional silos. Physical Review E, 59, 4408.

Clark, J. J., Qian, Q., Voller, V. R. \& Stefan, H. G. 2019. Hyporheic exchange in a gravel bed flume with and without traveling surface waves. Advances in Water Resources, 123, 120133.

Dallmann, J., Phillips, C., Teitelbaum, Y., Sund, N., Schumer, R., Arnon, S. \& Packman, A. 2020. Impacts of suspended clay particle deposition on sand-bed morphodynamics. Water Resources Research, 56, e2019WR027010.

Dumas, S., Arnott, R. \& Southard, J. B. 2005. Experiments on oscillatory-flow and combined-flow bed forms: implications for interpreting parts of the shallow-marine sedimentary record. Journal of Sedimentary research, 75, 501-513.

Elliott, A. H. \& Brooks, N. H. 1997. Transfer of nonsorbing solutes to a streambed with bed forms: Theory. Water Resources Research, 33, 123-136.

Faraci, C. \& Foti, E. 2001. Evolution of small scale regular patterns generated by waves propagating over a sandy bottom. Physics of Fluids, 13, 1624-1634.

Gong, W., Shen, J. \& Reay, W. G. 2007. The hydrodynamic response of the York River estuary to Tropical Cyclone Isabel, 2003. Estuarine, Coastal and Shelf Science, 73, 695-710.

Grant, W. D. \& Madsen, O. S. 1979. Combined wave and current interaction with a rough bottom. Journal of Geophysical Research: Oceans, 84, 1797-1808.

Hara, T. \& Mei, C. C. 1990. Centrifugal instability of an oscillatory flow over periodic ripples. Journal of Fluid Mechanics, 217, 1-32.

Healy, T., Wang, Y. \& Healy, J.-A. 2002. Muddy coasts of the world: processes, deposits and function, Elsevier. 
Huettel, M., Ziebis, W. \& Forster, S. 1996. Flow-induced uptake of particulate matter in permeable sediments. Limnology and Oceanography, 41, 309-322.

Karwan, D. L. \& Saiers, J. E. 2012. Hyporheic exchange and streambed filtration of suspended particles. Water Resources Research, 48.

Khelifa, A. \& Ouellet, Y. 2000. Prediction of sand ripple geometry under waves and currents. Journal of waterway, port, coastal, and ocean engineering, 126, 14-22.

Lapotre, M. G., Lamb, M. P. \& Mcelroy, B. 2017. What sets the size of current ripples? Geology, 45, 243-246.

Li, M. Z. \& Amos, C. L. 1998. Predicting ripple geometry and bed roughness under combined waves and currents in a continental shelf environment. Continental Shelf Research, 18, 941-970.

Li, M. Z. \& Amos, C. L. 1999. Field observations of bedforms and sediment transport thresholds of fine sand under combined waves and currents. Marine Geology, 158, 147-160.

Liang, H., Lamb, M. P. \& Parsons, J. D. 2007. Formation of a sandy near-bed transport layer from a fine-grained bed under oscillatory flow. Journal of Geophysical Research: Oceans, 112.

Malarkey, J., Baas, J. H., Hope, J. A., Aspden, R. J., Parsons, D. R., Peakall, J., Paterson, D. M., Schindler, R. J., Ye, L. \& Lichtman, I. D. 2015. The pervasive role of biological cohesion in bedform development. Nature communications, 6, 1-6.

Malarkey, J. \& Davies, A. G. 2012. A simple procedure for calculating the mean and maximum bed stress under wave and current conditions for rough turbulent flow based on method. Computers \& Geosciences, 43, 101-107. 
Mathisen, P. P. \& Madsen, O. S. 1996. Waves and currents over a fixed rippled bed: 2. Bottom and apparent roughness experienced by currents in the presence of waves. Journal of Geophysical Research: Oceans, 101, 16543-16550.

Miller, M. C. \& Komar, P. D. 1980. Oscillation sand ripples generated by laboratory apparatus. Journal of Sedimentary Research, 50, 173-182.

Myrow, P. M., Lamb, M. \& Ewing, R. 2018. Rapid sea level rise in the aftermath of a Neoproterozoic snowball Earth. Science, 360, 649-651.

Nedwell, D., Parkes, R. J., Upton, A. \& Assinder, D. 1993. Seasonal fluxes across the sedimentwater interface, and processes within sediments. Philosophical Transactions of the Royal Society of London. Series A: Physical and Engineering Sciences, 343, 519-529.

Nelson, T. R., Voulgaris, G. \& Traykovski, P. 2013. Predicting wave-induced ripple equilibrium geometry. Journal of Geophysical Research: Oceans, 118, 3202-3220.

Niño, Y., Lopez, F. \& Garcia, M. 2003. Threshold for particle entrainment into suspension. Sedimentology, 50, 247-263.

O'Hara Murray, R., Thorne, P. \& Hodgson, D. 2011. Intrawave observations of sediment entrainment processes above sand ripples under irregular waves. Journal of Geophysical Research: Oceans, 116.

Packman, A. I., Brooks, N. H. \& Morgan, J. J. 2000. A physicochemical model for colloid exchange between a stream and a sand streambed with bed forms. Water Resources Research, 36, 2351-2361.

Panagiotopoulos, I., Voulgaris, G. \& Collins, M. 1997. The influence of clay on the threshold of movement of fine sandy beds. Coastal Engineering, 32, 19-43. 
Parsons, D. R., Schindler, R. J., Hope, J. A., Malarkey, J., Baas, J. H., Peakall, J., Manning, A. J., Ye, L., Simmons, S. \& Paterson, D. M. 2016. The role of biophysical cohesion on subaqueous bed form size. Geophysical research letters, 43, 1566-1573.

Partheniades, E. 2009. Cohesive sediments in open channels: erosion, transport and deposition, Butterworth-Heinemann.

Pedocchi, F. \& García, M. 2009. Ripple morphology under oscillatory flow: 2. Experiments. Journal of Geophysical Research: Oceans, 114.

Perillo, M. M., Best, J. L. \& Garcia, M. H. 2014a. A new phase diagram for combined-flow bedforms. Journal of Sedimentary Research, 84, 301-313.

Perillo, M. M., Best, J. L., Yokokawa, M., Sekiguchi, T., Takagawa, T. \& Garcia, M. H. 2014b. A unified model for bedform development and equilibrium under unidirectional, oscillatory and combined-flows. Sedimentology, 61, 2063-2085.

Precht, E. \& Huettel, M. 2003. Advective pore-water exchange driven by surface gravity waves and its ecological implications. Limnology and Oceanography, 48, 1674-1684.

Ralston, D. K., Warner, J. C., Geyer, W. R. \& Wall, G. R. 2013. Sediment transport due to extreme events: The Hudson River estuary after tropical storms Irene and Lee. Geophysical Research Letters, 40, 5451-5455.

Rubin, D. M. \& Carter, C. L. 2005. Bedforms 4.0: MATLAB code for simulating bedforms and cross-bedding, US Geological Survey.

Scherer, M., Melo, F. \& Marder, M. 1999. Sand ripples in an oscillating annular sand-water cell. Physics of Fluids, 11, 58-67.

Snelgrove, P. \& Butman, C. 1995. Animal-sediment relationships revisited: cause versus effect. Oceanographic Literature Review, 8, 668. 
Soulsby, R. 1997. Dynamics of marine sands: a manual for practical applications, Thomas Telford.

Soulsby, R. \& Clarke, S. 2005. Bed shear-stress under combined waves and currents on smooth and rough beds (TR 137).

Southard, J. B. 1991. Experimental determination of bed-form stability. Annual Review of Earth and Planetary Sciences, 19, 423-455.

Staudt, F., Mullarney, J. C., Pilditch, C. A. \& Huhn, K. 2017. The role of grain-size ratio in the mobility of mixed granular beds. Geomorphology, 278, 314-328.

Stegner, A. \& Wesfreid, J. E. 1999. Dynamical evolution of sand ripples under water. Physical review E, 60, R3487.

Tanaka, H. \& Dang, V.T. 1996. Geometry of sand ripples due to combined wave-current flows. Journal of waterway, port, coastal, and ocean engineering, 122, 298-3000.

Van Der Mark, C., Blom, A. \& Hulscher, S. 2008. Quantification of variability in bedform geometry. Journal of Geophysical Research: Earth Surface, 113.

Van Der Werf, J. J., Magar, V., Malarkey, J., Guizien, K. \& O’Donoghue, T. 2008. 2DV modelling of sediment transport processes over full-scale ripples in regular asymmetric oscillatory flow. Continental Shelf Research, 28, 1040-1056.

Van Rijn, L. C. 2007. Unified view of sediment transport by currents and waves. I: Initiation of motion, bed roughness, and bed-load transport. Journal of Hydraulic engineering, 133, 649-667.

Wengrove, M., Foster, D., Lippmann, T., De Schipper, M. \& Calantoni, J. 2018. Observations of Time-Dependent Bedform Transformation in Combined Wave-Current Flows. Journal of Geophysical Research: Oceans, 123, 7581-7598. 
675 Woodruff, J. D., Irish, J. L. \& Camargo, S. J. 2013. Coastal flooding by tropical cyclones and sea$676 \quad$ level rise. Nature, 504, 44-52.

677 Wu, X., Baas, J. H., Parsons, D. R., Eggenhuisen, J., Amoudry, L., Cartigny, M., Mclelland, S., 678 Mouazé, D. \& Ruessink, G. 2018. Wave Ripple Development on Mixed Clay-Sand 679 Substrates: Effects of Clay Winnowing and Armoring. Journal of Geophysical Research: $680 \quad$ Earth Surface, 123, 2784-2801.

681 Wu, X; Fernández, R., Parsons, D. R., Baas, J. H., Malarkey, J. 2021. Laboratory measurement 682 of wave-current ripple development. figshare. Dataset. https://doi.org/10.6084/m9.figshare.16715578.v1 